\title{
Acute Brachial Plexopathy Caused by Burkitt's Lymphoma Infiltration
}

\author{
Kazumoto Shibuya, Sonoko Misawa, Shigeki Hirano and Satoshi Kuwabara
}

Key words: Burkitt's lymphoma, brachial plexopathy, magnetic resonance neurography

(Intern Med 52: 931, 2013)

(DOI: 10.2169/internalmedicine.52.9156)
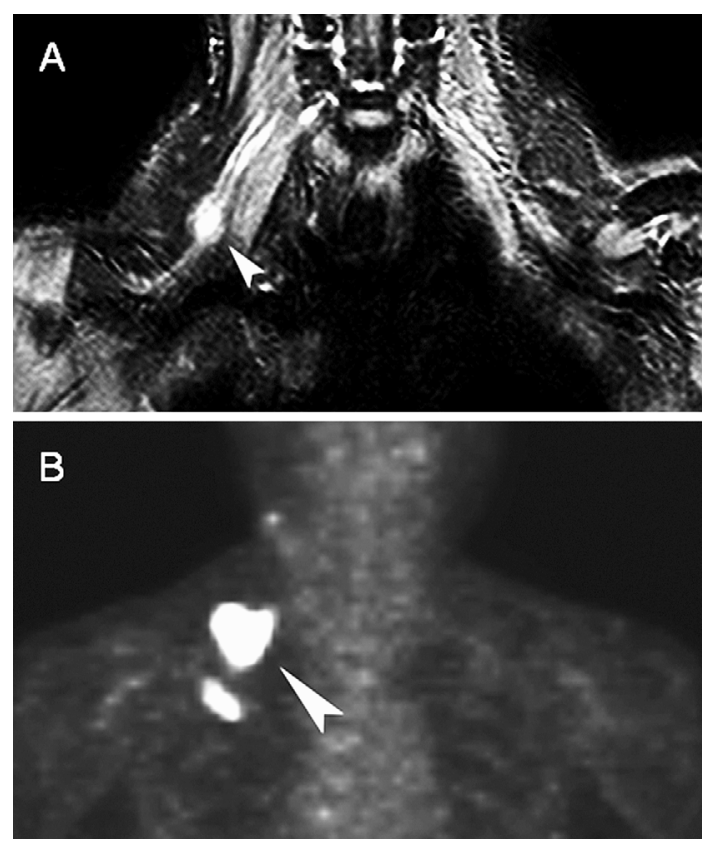

Picture.

A 63-year-old woman presented with weakness in the deltoid and biceps brachii muscles and paresthesia in the radial forearm which had progressed over the previous one week. She was initially suspected as having brachial plexus neuritis and was admitted to our hospital. Brachial plexus MRI with turbo short tau inversion recovery (STIR) and fluorodeoxy glucose-positron emission tomography (FDG-PET) disclosed a nodular mass that compressed the right upper trunk of the brachial plexus (Picture). CT revealed an ileocecal tumor, a biopsy of which showed histological evidence of Burkitt's lymphoma. The patient was treated with chemotherapy consisting of "Hyper CVAD" (cyclophosphamide, vindesine, adriamycin and dexamethasone), resulting in reduction of the size of the lymph node and gradual improvement in muscle weakness and sensory disturbance. STIR MRI is a useful screening technique for detecting enlarged cervical lymph nodes in the brachial plexus $(1,2)$. The present case suggests that, in patients with brachial plexopathy, the use of STIR MRI is informative for making a differential diagnosis between brachial plexus neuritis and compressive plexopathy.

The authors state that they have no Conflict of Interest (COI).

\section{References}

1. Kawai Y, Sumi M, Nakamura T. Turbo short tau inversion recovery imaging for metastatic node screening in patients with head and neck cancer. AJNR Am J Neuroradiol 27: 1283-1287, 2006.

2. van Es HW, Bollen TL, van Heesewijk HP. MRI of the brachial plexus: a pictorial review. Eur J Radiol 74: 391-402, 2010.

Department of Neurology, Graduate School of Medicine, Chiba University, Japan

Received for publication October 18, 2012; Accepted for publication December 17, 2012

Correspondence to Dr. Satoshi Kuwabara, kuwabara-s@faculty.chiba-u.jp

(C) 2013 The Japanese Society of Internal Medicine Journal Website: http://www.naika.or.jp/imonline/index.html 